\title{
Insights into the roles of hnRNP A2/B1 and $A X L$ in non-small cell lung cancer
}

\author{
XIAO-HAN QU ${ }^{1}$, JIN-LU LIU $^{2}$, XIN-WEN ZHONG ${ }^{1}, \mathrm{XI} \mathrm{LI}^{1}$ and QI-GANG ZHANG ${ }^{1 *}$ \\ ${ }^{1}$ Department of Thoracic Surgery, The First Hospital of China Medical University, Shenyang, Liaoning 110001; \\ ${ }^{2}$ Department of Ophthalmology, The Fourth Affiliated Hospital of China Medical University, \\ Shenyang, Liaoning 110034, P.R. China
}

Received August 13, 2014; Accepted June 2, 2015

DOI: $10.3892 / \mathrm{ol} .2015 .3457$

\begin{abstract}
Lung cancer has long been one of the most serious types of malignant tumor, and is associated with high incidence and mortality rates. Despite advancements in the comprehensive treatment of the disease, particularly with targeted therapeutic agents, there has been little improvement in the 5-year survival rates of patients. One of the leading causes of mortality in lung cancer is the lack of effective early diagnostic criteria. On this basis, the present study aimed to identify an index with potential in the early diagnosis and prognosis of lung cancer. The current study determined the expression of heterogeneous nuclear ribonucleoprotein (hnRNP) A2/B1 and AXL proteins in non-small cell lung cancer (NSCLC) tumor samples, and performed prognostic analysis of the collected clinical data to identify any association. In addition, RNA interference was performed to silence the expression of hnRNP A2/B1, allowing evaluation of its molecular and cellular functions, and determination of the mechanism of hnRNP A2/B1 in NSCLC by means of AXL mediation. It was identified that the positive expression rate of hnRNP A2/B1 and AXL proteins were significantly higher in NSCLC compared with paracancerous lung tissues $(\mathrm{P}<0.05)$. Furthermore, the expression of hnRNP A2/B1 protein was correlated with the expression AXL. Thus, the expression of hnRNP A2/B1 and AXL protein are factors affecting prognosis in patients with NSCLC. Of these, hnRNP A2/B1 appears to be an independent risk factor.
\end{abstract}

\section{Introduction}

Lung cancer has become one of the most serious malignant types of tumor, and is associated with high incidence and

Correspondence to: Dr Qi-Gang Zhang, Department of Thoracic Surgery, The First Hospital of China Medical University, 155 Nanjing North Street, Heping, Shenyang, Liaoning 110001, P.R. China

E-mail: zhangqigang88@yeah.net

Key words: heterogeneous nuclear ribonucleoprotein A2/B1, AXL receptor tyrosine kinase, non-small cell lung cancer mortality rates worldwide. According to a report by the American Cancer Society in 2013, the occurrence of lung cancer constitutes $14 \%$ of the total incidence of malignant tumors $(1,2)$. Furthermore, lung cancer is the second most common malignancy globally after prostatic and breast cancer, and accounts for 28 and $16 \%$ of mortalities caused by malignancies in men and women, respectively. Thus, lung cancer is the most lethal human malignancy (3). In fact, lung cancer has even higher incidence and mortality rates in China, with $\sim 85 \%$ of cases of lung cancer diagnosed as non-small cell lung cancer (NSCLC) (2). This indicates the importance of fundamental investigations into clinical treatment guidance for patients with NSCLC.

Recently, significant advancements have been made in the comprehensive treatment of lung cancer, particularly with targeted agents. Despite this, there has been little improvement in the 5-year survival rates of patients with lung cancer, with the rate remaining as low as $15 \%$. This is true even for those treated patients with surgery, constituting $\leq 40 \%$ of patients (3). One of the leading factors associated with this poor survival is the lack of effective early diagnostic criteria. In fact, the majority of patients are already in the aggressive stage when diagnosed with lung cancer (4). Another important factor is the lack of efficient treatment strategies for severe cases with marked resistance to multiple agents. On this basis, there is an urgent requirement to identify effective diagnostic criteria for the early diagnosis of lung cancer, as well as indexes for its prognosis, that together may contribute to improvements in the total survival rates.

The heterogeneous nuclear ribonucleoprotein (hnRNP) family are important in the process of mRNA transcription, shearing and splicing (5). The superfamily is composed of $>20$ members, the majority of which bind to the splicing sequences located within introns and exons to perform regulatory roles (6). Among them, the principle members are hnRNP A1, A2, A3 and B1. hnRNP A2 and B1 constitute the core, and are isomers of the same protein derived from the hnRNP A2/B1 gene. Thus, there are similarities in the sequence and function of these two proteins (7-9). Numerous studies have identified abnormally high expression of hnRNP A2/B1 in a variety of tumor types (10-14). According to previous reports, it is well-established that hnRNP A2/B1 serves as an early diagnostic indicator of 
lung cancer (15-17). However, it remains unclear whether it is effective as a prognostic criterion.

AXL belongs to the receptor tyrosine kinase (RTK) family of proteins (18). AXL, together with two other RTKs (TYRO3 and MER), constitutes the TAM tyrosine receptor sub-family. The three proteins share similar structures and functions (19-21). Structurally, TAM proteins are characterized by two immunoglobulin-like extra-cellular domains and two repeating fibronectin type III cytoplasmic kinase domains (19). They also share the same ligand, Gas6. Previous studies indicated that the activation of TAM, as well as the downstream signal transduction cascades, are key in various cellular functions and behaviors, including cell survival, proliferation, migration and adherence (18). High expression of AXL was also identified in a variety of tumors, and AXL appears to be important in the invasion and metastasis of lung cancer (22). More notably, He et al (23) performed RNA interference (RNAi) to reduce the expression of hnRNP A2/B1 in Colo16 cancer cells. Using high-throughput gene chip screening, marked differences were observed in the expression of 123 downstream target genes, including AXL, indicating a potential interaction between hnRNP A2/B1 and AXL.

The present study aimed to determine the expression of hnRNP A2/B1 and AXL in NSCLC and paracancerous lung control samples, as well as perform a prognostic analysis of the collected clinical data to explore any potential association. In addition, RNAi was performed to silence the expression of hnRNP A2/B1, on which basis molecular and cellular functions of hnRNP A2/B1 were evaluated to determine its mechanism in NSCLC, possibly by means of AXL mediation. Written informed consent was obtained from all patients.

\section{Materials and methods}

Tissue microarray. The tissue microarray was purchased from the National Biological Chip Center (Shanghai, China) and constructed using 150 resected NSCLC and paracancerous lung tissues samples (two sets of chips with serial sections). Matched cancerous and paracancerous samples were collected from the First Hospital of China Medical University (Shenyang, China) between 2004 and 2007 during surgery for pulmonary lobectomy or total pneumonectomy. Following the exclusion of cases with incomplete data, such as gender, age, tumor size, histological type, TNM American Joint Committee on Cancer classification (24), degree of differentiation, lymph node metastasis and prognostic data, 134 cases were available for prognostic analysis. The most recent follow-up time was July 2012. The study was approved by the ethics committee of the First Affiliated Hospital of China Medical University.

Reagents. Mouse monoclonal anti-human hnRNP A2/B1 (cat no. ab6102) and rabbit polyclonal anti-human AXL (cat no. ab72069) antibodies were purchased from Abcam (Cambridge, UK), and monoclonal mouse anti-human $\beta$-actin (cat no. SC-47778) antibodies were purchased from Santa Cruz Biotechnology, Inc. (Dallas, TX, USA). Additionally, the UltraSensitive ${ }^{\mathrm{TM}}$ SP IHC and MaxVision $^{\mathrm{TM}}$ DAB kits were purchased from Maxim Biotech, Inc. (Rockville, MD, USA).
Immunohistochemical streptavidin-peroxidase analysis. The tissue chips were dewaxed with dimethylbenzene two times (15 min each), then washed twice with $100 \%$ ethanol (5 min each), once with $95 \%$ ethanol (2 min each), once with $85 \%$ ethanol ( $2 \mathrm{~min}$ each), once with $75 \%$ ethanol ( 2 min each) and three times with distilled water (3 min each). Endogenous peroxidase was blocked with liquid-A of the UltraSensitive SP IHC kit for $30 \mathrm{~min}$ and then washed three times with phosphate-buffered saline (PBS; 3 min each). Antigen retrieval was performed at a high pressure using citric acid for $3 \mathrm{~min}$, cooled to room temperature and washed three times with PBS (3 min each). The non-immune serum (liquid-B, UltraSensitive SP IHC kit) was added prior incubating the chips at $37^{\circ} \mathrm{C}$ for $30 \mathrm{~min}$ to block non-specific antigens. Excess serum was discarded, primary hnRNP A2/B1 (1:500 dilution) and AXL (1:100 dilution) antibodies were added, and the tissue chips were stored at $4^{\circ} \mathrm{C}$ overnight. Secondary antibody (solution-C, UltraSensitive SP IHC kit) was added and incubated at $37^{\circ} \mathrm{C}$ for $30 \mathrm{~min}$. After washing three times with PBS (3 min each), the coloring conditions were observed under microscopy by adding solution-D of the UltraSensitive SP IHC kit and the DAB reagents. The reaction was terminated and stained with hematoxylin for $3 \mathrm{~min}$, differentiated with $1 \%$ hydrochloric acid ethanol and rinsed in water for $10 \mathrm{~min}$. Dehydration with ethanol was performed in gradients prior to clearing in xylene and mounting with neutral gum.

Classification. The results of the immunohistochemical analysis were classified according to the following criterion: The proportion of positive cells $(<30 \%, 1$ point; $30-60 \%, 2$ point; $>60 \%, 3$ points) and the color of staining (colorless or light yellow, 1 point; yellow, 2 points; brown, 3 points). The final scores were obtained by multiplying the two integrates and were used to determine the following classifications: $1-2$, negative expression; and 3-9, positive expression. All scoring was performed by two independent pathologists and the mean of the scores was used as the final result.

Statistical analysis. Comparisons were performed using t-tests, and correlation analysis between the expression of hnRNP A2/B1 and AXL in the lung tissue samples was conducted using the Pearson's correlation method. The clinical data was analyzed by performing a $\chi^{2}$-test or Fisher's exact probability. Survival curves were constructed according to the Kaplan-Meier method and analyzed using log-rank tests. Furthermore, univariate and multivariate Cox regression analysis was used to identify independent prognostic factors. SPSS software (version 18.0; IBM SPSS, Armonk, NY, USA) was used to perform all statistical analyses. $\mathrm{P}<0.05$ was considered to indicate a statistically significant difference.

\section{Results}

Protein expression levels of hnRNP A2/B1 in NSCLC and paracancerous tissue samples. In the present study, a total of 134 NSCLC and paracancerous tissue chip samples were collected. Immunohistochemical staining was used to identify that hnRNP A2/B1 protein is located in the nucleus and cytoplasm of invasive adenocarcinoma (Fig. 1A) and highly differentiated squamous cell carcinoma (Fig. 1B). High 
Table I. Expression of hnRNP A2/B1 in NSCLC and paracancerous lung tissues.

\begin{tabular}{lccccr}
\hline & & \multicolumn{2}{c}{ hnRNP A2/B1 expression, $\mathrm{n}$} & & \\
\cline { 3 - 5 } Lung tissue & Total cases, $\mathrm{n}$ & Negative & Positive & Positive rate, \% & P-value \\
\hline NSCLC & 134 & 47 & 87 & 67.9 & $0.000^{\text {a }}$ \\
Paracancerous & 134 & 121 & 13 & 9.7 & \\
\hline
\end{tabular}

${ }^{\mathrm{a}} \mathrm{P}<0.05$. hnRNP, heterogeneous nuclear ribonucleoprotein; NSCLC, non-small cell lung cancer.
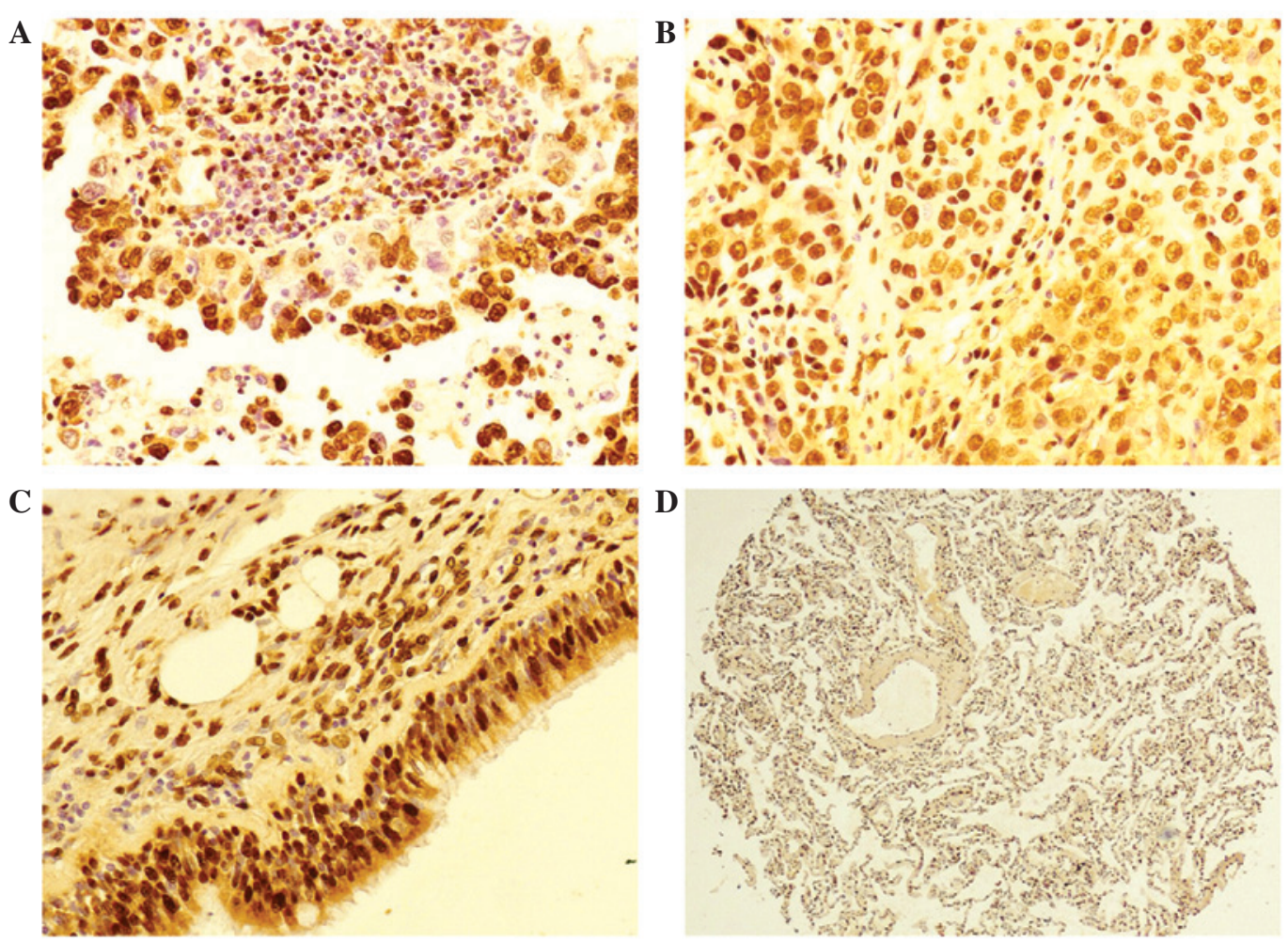

Figure 1. Expression of heterogeneous nuclear ribonucleoprotein A2/B1 in the nucleus and cytoplasm of (A) invasive adenocarcinoma (B) highly differentiated squamous cell carcinoma, (C) hyperplastic bronchial epithelia (magnification, x200) and (D) paracancerous lung tissue samples (magnification, x50; hematoxylin stain).

hnRNP A2/B1 expression was observed in hyperplastic bronchial epithelia (Fig. 1C), however, little expression of hnRNP A2/B1 was observed in the paracancerous lung tissues (Fig. 1D). According to statistical analysis, there was a significantly greater rate of positive hnRNP A2/B1 expression in NSCLC compared with paracancerous lung tissues $(\mathrm{P}<0.001$; Table I).

Association between hnRNP A2/B1 expression and clinicopathological factors. According to statistical analysis of the clinical data, it was identified that the expression of hnRNP A2/B1 was significantly correlated with the differentiation of lesions in 134 cases of NSCLC. The lower the degree of differentiation, the greater the positive expression of hnRNP A2/B1 ( $\mathrm{P}=0.001)$. Furthermore, according to the TNM classification system, there was a significant increase in positive hnRNP A2/B1 expression in phases III/IV compared with phases I/II ( $\mathrm{P}=0.007)$. However, hnRNP A2/B1 expression was not significantly associated with gender, age, histological type, lymph node metastasis or tumor size (Table II).

Association between hnRNP A2/B1 expression and survival. To analyze survival, Kaplan-Meier plots were constructed for hnRNP A2/B1-positive and -negative patients (Fig. 2A). The median survival time was $54.7 \pm 3.8$ months for hnRNP A2/B1-positive patients and 82.4 \pm 3.5 months for hnRNP A2/B1-negative patients. There was a statistically significant difference between survival in these two groups (log-rank test, $\mathrm{P}<0.001)$. Compared with other clinical factors, such as gender, histological type and degree of differentiation, positive expression of hnRNP A2/B1 was identified as an independent risk factor that may influence the prognosis of patients with NSCLC ( $\mathrm{P}=0.001$; Table III), according to multivariate Cox regression analysis.

Protein expression levels of AXL in NSCLC and paracancerous tissue samples. Immunohistochemical analysis of 134 NSCLC 
Table II. Association between hnRNP A2/B1 expression and clinicopathological factors in patients with NSCLC.

\begin{tabular}{|c|c|c|c|c|c|}
\hline \multirow[b]{2}{*}{ Clinicopathological factor } & \multirow[b]{2}{*}{ Cases, n (n=134) } & \multicolumn{2}{|c|}{$\begin{array}{c}\text { hnRNP A2/B1 } \\
\text { expression }\end{array}$} & \multirow[b]{2}{*}{ Positive rate, $\%$} & \multirow[b]{2}{*}{ P-value } \\
\hline & & - & + & & \\
\hline \multicolumn{6}{|l|}{ Gender } \\
\hline Male & 99 & 35 & 64 & 64.6 & \multirow[t]{2}{*}{1.000} \\
\hline Female & 35 & 12 & 23 & 65.7 & \\
\hline \multicolumn{6}{|l|}{ Age, years } \\
\hline$\leq 60$ & 58 & 19 & 39 & 67.2 & \multirow[t]{2}{*}{0.716} \\
\hline$>60$ & 76 & 28 & 48 & 63.2 & \\
\hline \multicolumn{6}{|l|}{ Histological type } \\
\hline Adenocarcinoma & 67 & 22 & 45 & 67.2 & \multirow[t]{2}{*}{0.718} \\
\hline Squamous cell carcinoma & 67 & 25 & 42 & 62.7 & \\
\hline \multicolumn{6}{|l|}{ Degree of differentiation } \\
\hline High & 23 & 13 & 10 & 43.5 & \multirow[t]{3}{*}{$0.001^{\mathrm{a}}$} \\
\hline Middle & 73 & 29 & 44 & 60.3 & \\
\hline Low & 38 & 5 & 33 & 86.8 & \\
\hline \multicolumn{6}{|l|}{ TNM classification } \\
\hline $\mathrm{I} / \mathrm{II}$ & 99 & 41 & 58 & 58.6 & \multirow[t]{2}{*}{$0.013^{\mathrm{a}}$} \\
\hline III/IV & 35 & 6 & 29 & 82.9 & \\
\hline \multicolumn{6}{|l|}{ Lymphatic metastasis } \\
\hline Yes & 60 & 20 & 40 & 66.7 & \multirow[t]{2}{*}{0.720} \\
\hline No & 74 & 27 & 47 & 63.5 & \\
\hline \multicolumn{6}{|l|}{ Tumor size, $\mathrm{cm}$} \\
\hline$\leq 3$ & 48 & 21 & 27 & 56.3 & \multirow[t]{2}{*}{0.133} \\
\hline$>3$ & 86 & 26 & 60 & 69.8 & \\
\hline
\end{tabular}

${ }^{\mathrm{a}} \mathrm{P}<0.05$. hnRNP, heterogeneous nuclear ribonucleoprotein; NSCLC, non-small cell lung cancer.
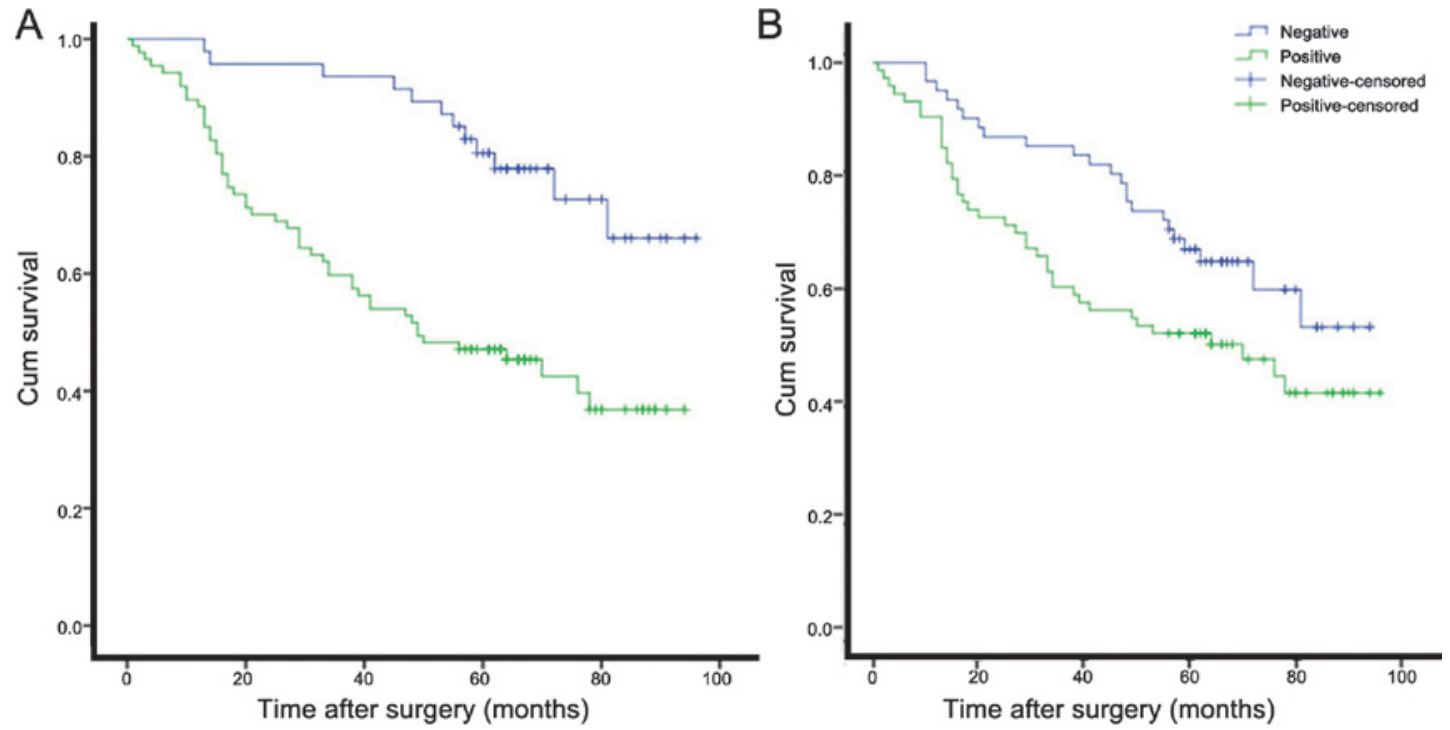

Figure 2. Kaplan-Meier plots for patients with different expression rates of (A) heterogeneous nuclear ribonucleoprotein A2/B1 and (B) AXL. Cum, cumulative.

and paracancerous tissue samples revealed that AXL protein is predominantly located in the cytoplasm (Fig. 3), with little expression in the nucleus. Furthermore, statistical analysis identified a significantly greater rate of positive AXL expression in NSCLC compared with in paracancerous lung tissues $(\mathrm{P}<0.05$; Table IV). 
Table III. Univariate and multivariate regression analysis of clinical data and prognosis with Cox model.

\begin{tabular}{lcccc}
\hline & \multicolumn{2}{c}{ Univariate regression analysis } & & Multivariate regression analysis \\
\cline { 2 - 3 } Index & $95 \%$ confidence interval & P-value & 95\% confidence interval & - \\
\hline Gender & $0.926(0.704-1.219)$ & 0.584 & - & - \\
Tumor size & $0.756(0.572-1.000)$ & $0.050^{\mathrm{a}}$ & - & - \\
Histological type & $1.083(0.844-1.390)$ & 0.532 & - & - \\
Degree of differentiation & $0.997(0.687-1.446)$ & 0.986 & $0.016^{\mathrm{a}}$ \\
TNM classification & $1.800(1.378-2.351)$ & $<0.001^{\mathrm{a}}$ & & $1.558(1.086-2.237)$ \\
Lymphatic metastasis & $2.234(1.396-3.867)$ & $0.001^{\mathrm{a}}$ & $1.490(0.809-2.746)$ & 0.201 \\
Age & $1.910(1.112-3.280)$ & $0.019^{\mathrm{a}}$ & $2.119(1.228-3.655)$ & $0.007^{\mathrm{a}}$ \\
hnRNPA2/B expression & $0.313(0.166-0.588)$ & $<0.001^{\mathrm{a}}$ & $2.928(1.539-5.573)$ & $0.001^{\mathrm{a}}$ \\
\hline
\end{tabular}

${ }^{\mathrm{a}} \mathrm{P}<0.05$. hnRNP, heterogeneous nuclear ribonucleoprotein.

A

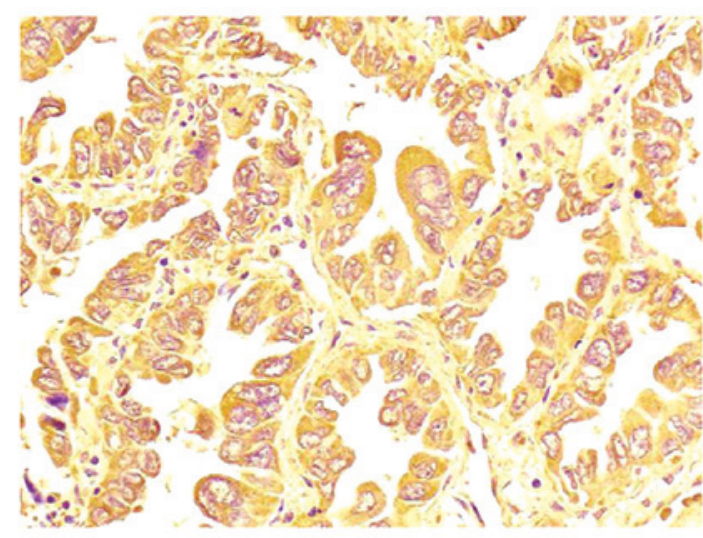

C

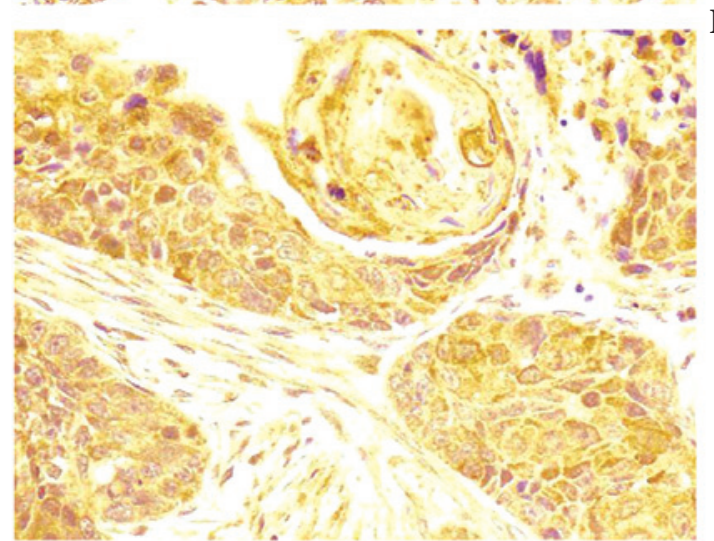

B
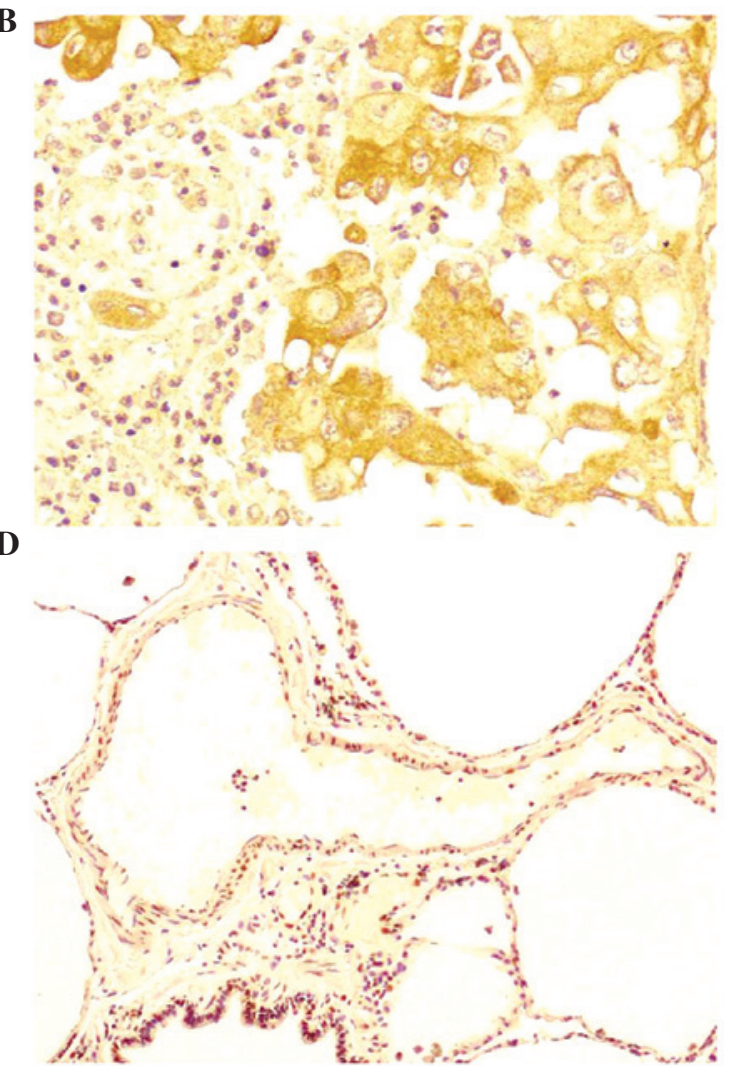

Figure 3. Immnuohistochemical expression of AXL in the nucleus and cytoplasm of (A) highly differentiated adenocarcinoma, (B) low/moderately differentiated adenocarcinoma and (C) highly differentiated squamous cell carcinoma non-small cell lung cancer tissue samples (magnification, x200), and (D) paracancerous lung tissue samples (magnification, x100; hematoxylin stain).

Association between AXL expression and clinicopathological factors. Following statistical analysis of the clinical data, it was identified that the expression of AXL is significantly correlated with the differentiation of lesions in the 134 cases of NSCLC investigated. The lower the degree of differentiation, the greater the positive expression of AXL $(\mathrm{P}=0.001)$. According to the TNM classification system, there was a significant increase in the expression of AXL in TNM phases II/III/IV compared with phase $\mathrm{I}(\mathrm{P}=0.005)$. However, AXL expression was not significantly associated with other clinical factors, such as gender, age, histological type, lymph node metastasis and tumor size (Table V).

Association between AXL expression and survival. To analyze survival, Kaplan-Meier plots were constructed for AXL-positive and -negative patients (Fig. 2B). The median survival time was 58.2 \pm 4.3 months for AXL-positive patients and 71.8 \pm 3.8 months for AXL-negative patients. There was a statistically significant difference between survival in these two groups (log-rank test; $\mathrm{P}=0.042$ ). According to univariate 
Table IV. Expression of AXL in NSCLC and paracancerous lung tissues.

\begin{tabular}{|c|c|c|c|c|c|}
\hline \multirow[b]{2}{*}{ Lung tissue } & \multirow[b]{2}{*}{ Total cases, $\mathrm{n}$} & \multicolumn{2}{|c|}{ AXL expression, $\mathrm{n}$} & \multirow[b]{2}{*}{ Positive rate, $\%$} & \multirow[b]{2}{*}{ P-value } \\
\hline & & Negative & Positive & & \\
\hline NSCLC & 134 & 61 & 73 & 54.5 & $0.001^{\mathrm{a}}$ \\
\hline Paracancerous & 134 & 95 & 39 & 29.1 & \\
\hline
\end{tabular}

${ }^{\mathrm{a}} \mathrm{P}<0.05$. NSCLC, non-small cell lung cancer.

Table V. Association between AXL expression and clinicopathological factors in patients with NSCLC.

\begin{tabular}{|c|c|c|c|c|c|}
\hline \multirow[b]{2}{*}{ Clinicopathological factor } & \multirow[b]{2}{*}{ Cases, $n(n=134)$} & \multicolumn{2}{|c|}{$\begin{array}{c}\text { AXL } \\
\text { expression }\end{array}$} & \multirow[b]{2}{*}{ Positive rate, $\%$} & \multirow[b]{2}{*}{$\mathrm{P}$-value } \\
\hline & & - & + & & \\
\hline \multicolumn{6}{|l|}{ Gender } \\
\hline Male & 99 & 42 & 57 & 57.6 & \multirow[t]{2}{*}{0.242} \\
\hline Female & 35 & 19 & 16 & 45.7 & \\
\hline \multicolumn{6}{|l|}{ Age, years } \\
\hline$\leq 60$ & 58 & 25 & 33 & 56.9 & \multirow[t]{2}{*}{0.727} \\
\hline$>60$ & 76 & 36 & 40 & 53.6 & \\
\hline \multicolumn{6}{|l|}{ Histological type } \\
\hline Adenocarcinoma & 67 & 31 & 36 & 53.7 & \multirow[t]{2}{*}{1.000} \\
\hline Squamous cell carcinoma & 67 & 30 & 37 & 55.2 & \\
\hline \multicolumn{6}{|l|}{ Degree of differentiation } \\
\hline High & 23 & 17 & 6 & 26.1 & \multirow[t]{3}{*}{$0.001^{\mathrm{a}}$} \\
\hline Middle & 73 & 37 & 36 & 49.3 & \\
\hline Low & 38 & 7 & 31 & 81.6 & \\
\hline \multicolumn{6}{|l|}{ TNM classification } \\
\hline I & 23 & 17 & 6 & 26.1 & \multirow[t]{2}{*}{$0.005^{\mathrm{a}}$} \\
\hline II/III/IV & 111 & 44 & 67 & 60.4 & \\
\hline \multicolumn{6}{|l|}{ Lymphatic metastasis } \\
\hline Yes & 60 & 23 & 37 & 61.7 & \multirow[t]{2}{*}{0.092} \\
\hline No & 74 & 38 & 36 & 48.7 & \\
\hline \multicolumn{6}{|l|}{ Tumor size, $\mathrm{cm}$} \\
\hline$\leq 3$ & 48 & 26 & 22 & 45.8 & \multirow[t]{2}{*}{0.167} \\
\hline$>3$ & 86 & 35 & 51 & 59.3 & \\
\hline
\end{tabular}

${ }^{\mathrm{a}} \mathrm{P}<0.05$. NSCLC, non-small cell lung cancer.

Cox regression analysis, the positive expression of AXL was identified as an independent risk factor that may influence prognosis in NSCLC $(\mathrm{P}=0.045$; Table VI).

Correlation between the expression of hnRNP A2/B1 and AXL. Pearson's correlation of the expression of hnRNP A2/B1 and AXL identified an unexpectedly high correlation, with a coefficient of 0.459 ( $\mathrm{P}<0.001$; data not shown). Thus, there was a statistically significant correlation between the expression of hnRNP A2/B1 and AXL in the 134 cases of NSCLC analyzed in the current study. In addition, Fig. 4 indicates the staining patterns of hnRNP A2/B1 and AXL in different cases of NSCLC. It was observed that the expression of hnRNP A2/B1 and AXL correlated well in the same tissue, with correlation increasing as the degree of tissue differentiation reduced.

\section{Discussion}

In the present study, the expression of hnRNP A2/B1 was examined in NSCLC and paracancerous tissue samples. The association between hnRNP A2/B1 expression and the prognosis of patients with NSCLC was investigated by analyzing the statistical correlation between hnRNP A2/B1 expression 
Table VI. Univariate and multivariate Cox regression analysis of clinical data and prognosis of patients with NSCLC.

\begin{tabular}{|c|c|c|c|c|}
\hline \multirow[b]{2}{*}{ Index } & \multicolumn{2}{|c|}{ Univariate regression analysis } & \multicolumn{2}{|c|}{ Multivariate regression analysis } \\
\hline & $95 \%$ confidence interval & P-value & $95 \%$ confidence interval & P-value \\
\hline Gender & $0.926(0.704-1.219)$ & 0.584 & - & - \\
\hline Tumor size & $0.756(0.572-1.000)$ & $0.050^{\mathrm{a}}$ & - & - \\
\hline Histological type & $1.083(0.844-1.390)$ & 0.532 & - & - \\
\hline Degree of differentiation & $0.997(0.687-1.446)$ & 0.986 & - & - \\
\hline TNM classification & $1.800(1.378-2.351)$ & $<0.001^{\mathrm{a}}$ & $1.733(1.219-2.464)$ & $0.002^{\mathrm{a}}$ \\
\hline Lymphatic metastasis & $2.234(1.396-3.867)$ & $0.001^{\mathrm{a}}$ & $1.291(0.707-2.357)$ & 0.405 \\
\hline Age & $1.910(1.112-3.280)$ & $0.019^{\mathrm{a}}$ & $2.025(1.173-3.497)$ & $0.011^{\mathrm{a}}$ \\
\hline AXL expression & $1.696(1.012-2.841)$ & $0.045^{\mathrm{a}}$ & $1.406(0.830-2.383)$ & 0.206 \\
\hline
\end{tabular}

${ }^{\mathrm{a}} \mathrm{P}<0.05$. NSCLC, non-small cell lung cancer.
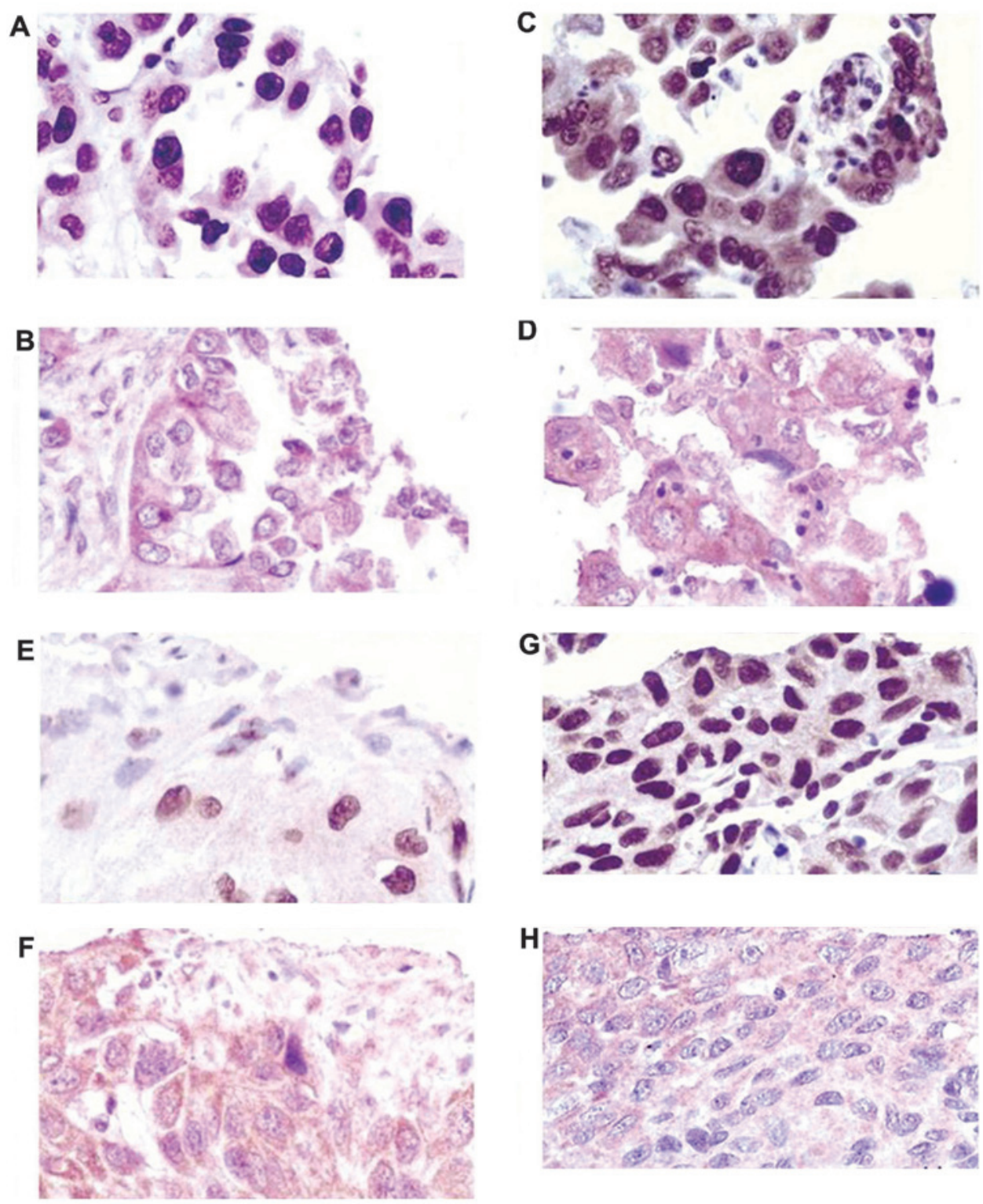

Figure 4. Expression of heterogeneous nuclear ribonucleoprotein (hnRNP) A2/B1 and AXL in samples of highly and poorly differentiated (A-D) adenocarcinoma and (E-H) squamous cell carcinoma. Staining of hnRNP A2/B1 in (A) highly and (C) poorly differentiated adenocarcinoma; AXL in (B) highly and (D) poorly differentiated adenocarcinoma; hnRNP A2/B1 in (E) highly and (G) poorly differentiated squamous cell carcinoma; and AXL in (F) highly and (H) poorly differentiated squamous cell carcinoma samples (magnification, $\mathrm{x} 400$; hematoxylin stain). 
and survival, as well as numerous clinicopathological factors.

The present study identified that the expression of hnRNP A2/B1 was predominantly located in the nucleus of cells, followed by the cytoplasm. This indicates the potential transfer of hnRNP A2/B1 from the cytoplasm to the nucleus, which was previously associated with tumor progression (25). The results of tissue microarray assays demonstrated that the rate of positive hnRNP A2/B1 expression was significantly higher in lung tumor than in paracancerous lung tissues. Furthermore, analysis of clinical factors revealed that positive expression of hnRNP A2/B1 was significantly higher in TNM stages III-IV compared with stages I-II $(\mathrm{P}=0.013)$. In other words, as NSCLC progresses, hnRNP A2/B1 expression increases. It was also identified that the expression of hnRNP A2/B1 is highly associated with the degree of tumor differentiation. Thus, the lower differentiation, the higher level of positive hnRNP A2/B1 expression. This indicates that the expression of hnRNP A2/B1 increases as the NSCLC becomes more severe.

Based on the aforementioned data, it is proposed that hnRNP A2/B1 may serve as a prognostic factor in NSCLC. This proposal is supported by the results of the current survival analysis. In addition to the log-rank test, Kaplan-Meier survival curves clarified a negative correlation between positive expression of hnRNP A2/B1 and survival rates of patients with NSCLC $(\mathrm{P}=0.000)$. Thus, high positive expression of hnRNP A2/B1 indicates an increased risk of patients with NSCLC exhibiting a poor prognosis. By using the multivariate Cox regression model to analyze the data, it was demonstrated that positive expression of hnRNP A2/B1 may be an independent risk factor for the prognosis of NSCLC $(\mathrm{P}=0.001)$.

He et al (23) previously reported that differences in the expression of 123 downstream target genes in Colo16 squamous carcinoma cells following RNAi silencing of hnRNP A2/B1 expression by means of high-throughput gene chip screening. Among them, AXL expression was affected, indicating a potential interaction between hnRNP A2/B1 and AXL. Similar to the results reported by Linger et al (26), the current study revealed that positive expression of AXL was significantly higher in lung tumors than in paracancerous lung tissues. Additional investigation of clinical data indicated that AXL is highly associated with the prognosis of lung cancer, using univariate (but not multivariate) Cox regression models. Abnormally high positive expression of AXL may be involved in the processes of apoptosis and tumor invasion (27), and, thus, associated with the degree of tumor differentiation and clinical TNM stage classification. A pair-wise t-test of protein expression demonstrated a significant correlation between hnRNP A2/B1 and AXL expression in the same tissue microarray $(\mathrm{P}<0.05)$.

In conclusion, the present study identified a significant increase in the protein expression of hnRNP A2/B1 and AXL in NSCLC compared with paracancerous lung tissue samples. Thus, hnRNP A2/B1 and AXL constitute independent risk factors for the prognosis of patients with NSCLC. In addition, the results of immunohistochemical analyses indicated a correlation between the expressions of hnRNP A2/B1 and AXL. Therefore, the present study provides the basis for the potential use of hnRNP A2/B1, as well as AXL, as clinicial prognostic criterion in NSCLC.

\section{References}

1. Siegel R, Naishadham D and Jemal A: Cancer statistics, 2013. CA Cancer J Clin 63: 11-30, 2013.

2. Yang Y, Li H, Hou S, Hu B, Liu J and Wang J: The noncoding RNA expression profile and the effect of lncRNA AK126698 on cisplatin resistance in non-small-cell lung cancer cell. PLoS One 8: e65309, 2013.

3. Grutters JP, Kessels AG, Pijls-Johannesma M, De Ruysscher D, Joore MA and Lambin P: Comparison of the effectiveness of radiotherapy with photons, protons and carbon-ions for non-small cell lung cancer: A meta-analysis. Radiother Oncol 95: 32-40, 2010.

4. Vansteenkiste J, Crinò L, Dooms C, Douillard JY, Faivre-Finn C, Lim E, Rocco G, Senan S, Van Schil P, Veronesi G, et al; Panel Members: 2nd ESMO Consensus Conference on Lung Cancer: Early-stage non-small-cell lung cancer consensus on diagnosis, treatment and follow-up. Ann Oncol 25:1462-1474, 2014.

5. Han SP, Tang YH and Smith R: Functional diversity of the hnRNPs: Past, present and perspectives. Biochem J 430: 379-392, 2010.

6. Majumder M, Yaman I, Gaccioli F, Zeenko VV, Wang C, Caprara MG, Venema RC, Komar AA, Snider MD and Hatzoglou M: The hnRNA-binding proteins hnRNP L and PTB are required for efficient translation of the Cat-1 arginine/lysine transporter mRNA during amino acid starvation. Mol Cell Biol 29: 2899-2912, 2009.

7. Hutchison S, LeBel C, Blanchette M and Chabot B: Distinct sets of adjacent heterogeneous nuclear ribonucleoprotein (hnRNP) A1/A2 binding sites control 5' splice site selection in the hnRNP A1 mRNA precursor. J Biol Chem 277: 29745-29752, 2002

8. Han K, Yeo G, An P, Burge CB and Grabowski PJ: A combinatorial code for splicing silencing: UAGG and GGGG motifs. PLoS Biol 3: e158, 2005.

9. Dreyfuss G, Kim VN and Kataoka N: Messenger-RNA-binding proteins and the messages they carry. Nat Rev Mol Cell Biol 3: 195-205, 2002.

10. Chettouh H, Fartoux L, Aoudjehane L, Wendum D, Clapéron A, Chrétien Y, Rey C, Scatton O, Soubrane O, Conti F, et al: Mitogenic insulin receptor-A is overexpressed in human hepatocellular carcinoma due to EGFR-mediated dysregulation of RNA splicing factors. Cancer Res 73: 3974-3986, 2013.

11. Chen Z-Y, Cai L, Zhu J, Chen M, Chen J, Li ZH, Liu XD, Wang SG, Bie P, Jiang P, et al: Fyn requires HnRNPA2B1 and Sam68 to synergistically regulate apoptosis in pancreatic cancer. Carcinogenesis 32: 1419-1426, 2011.

12. Golan-Gerstl R, Cohen M, Shilo A, Suh SS, Bakàcs A, Coppola L and Karni R: Splicing factor hnRNP A2/B1 regulates tumor suppressor gene splicing and is an oncogenic driver in glioblastoma. Cancer Res 71: 4464-4472, 2011.

13. Santarosa M, Del Col L, Viel A, Bivi N, D'Ambrosio C, Scaloni A, Tell G and Maestro R: BRCA1 modulates the expression of hnRNPA2B1 and KHSRP. Cell Cycle 9: 4666-4673, 2010.

14. He Y, Brown MA, Rothnagel JA, Saunders NA and Smith R: Roles of heterogeneous nuclear ribonucleoproteins A and B in cell proliferation. J Cell Sci 118: 3173-3183, 2005.

15. Tauler J, Zudaire E, Liu H, Shih J and Mulshine JL: hnRNP A2/B1 modulates epithelial-mesenchymal transition in lung cancer cell lines. Cancer Res 70: 7137-7147, 2010.

16. Katsimpoula S, Patrinou-Georgoula M, Makrilia N, Dimakou K, Guialis A, Orfanidou D and Syrigos KN: Overexpression of hnRNPA2/B1 in bronchoscopic specimens: A potential early detection marker in lung cancer. Anticancer Res 29: 1373-1382, 2009.

17. Fielding P, Turnbull L, Prime W, Walshaw M and Field JK: Heterogeneous nuclear ribonucleoprotein A2/B1 up-regulation in bronchial lavage specimens: A clinical marker of early lung cancer detection. Clinical Cancer Res 5: 4048-4052, 1999.

18. Korshunov VA: Axl-dependent signalling: A clinical update. Clin Sci (Lond) 122: 361-368, 2012.

19. Rothlin CV, Leighton JA and Ghosh S: Tyro3, Axl, and Mertk receptor signaling in inflammatory bowel disease and colitis-associated cancer. Inflamm Bowel Dis 20: 1472-1480, 2014.

20. Wu H, Tang H, Chen Y, Wang H and Han D: High incidence of distal vaginal atresia in mice lacking Tyro3 RTK subfamily. Molecular reproduction and development 75: 1775-1782, 2008. 
21. Wang H, Chen SU, Chen Y, Wang H, Wu H, Tang H, Xiong W, Ma J, Ge Y, Lu Q and Han D: The role of Tyro 3 subfamily receptors in the regulation of hemostasis and megakaryocytopoiesis. Haematologica 92: 643-650, 2007.

22. Mudduluru G, Ceppi P, Kumarswamy R, Scagliotti GV, Papotti M and Allgayer H: Regulation of Axl receptor tyrosine kinase expression by miR-34a and miR-199a/b in solid cancer. Oncogene 30: 2888-2899, 2011.

23. He Y, Rothnagel JA, Epis MR, Leedman PJ and Smith R: Downstream targets of heterogeneous nuclear ribonucleoprotein A2 mediate cell proliferation. Mol Carcinog 48: 167-179, 2009.

24. Edge SB and Compton CC: The American Joint Committee on Cancer: The 7th edition of the AJCC cancer staging manual and the future of TNM. Ann Surg Oncol 17: 1471-1474, 2010.
25. Man YG, Martinez A, Avis IM, Hong SH, Cuttitta F, Venzon DJ and Mulshine JL: Phenotypically different cells with heterogeneous nuclear ribonucleoprotein A2/B1 overexpression show similar genetic alterations. Am J Respir Cell Mol Biol 23: 636-645, 2000 .

26. LingerRM, Cohen RA, Cummings CT, Sather S, Migdall-Wilson J, Middleton DH, Lu X, Barón AE, Franklin WA, Merrick DT, et al: Mer or Axl receptor tyrosine kinase inhibition promotes apoptosis, blocks growth and enhances chemosensitivity of human non-small cell lung cancer. Oncogene 32: 3420-3431, 2013.

27. Zhang Z, Lee JC, Lin L, Olivas V, Au V, LaFramboise T, Abdel-Rahman M, Wang X, Levine AD, Rho JK, et al: Activation of the AXL kinase causes resistance to EGFR-targeted therapy in lung cancer. Nat Genet 44: 852-860, 2012. 